\title{
Seismic Response of Reinforced Concrete Columns
}

\author{
Halil Sezen and Muhammad S. Lodhi \\ Department of Civil and Environmental Engineering and Geodetic Science, \\ The Ohio State University, Columbus, Ohio,
}

USA

\section{Introduction}

There are a large number of reinforced concrete buildings in seismically active areas of the world that are not built in accordance with modern seismic design provisions such as those published by American Concrete Institution ([ACI] Committee 318, 2008). In the United States and other parts of the developed world, these buildings were constructed between 1930s to mid 1970s according to the building code requirements of that time. Even today, in low to moderate seismic regions and in some developing countries that are in process of developing and implementing their seismic codes, reinforced concrete structures are being designed and built without essential seismic details deemed vital to withstand large lateral loads. These buildings often have low lateral displacement capacities and undergo rapid degradation of shear strength and axial load carrying capacity during strong ground motions and hence are extremely vulnerable to excessive structural damage or collapse during future earthquakes.

In the past, the earthquakes have caused wide spread damage to the reinforced concrete structures with inadequate seismic design and construction practices. For example, during Kashmir (Pakistan) earthquake of 2005 and Haiti earthquake of 2010, extensive structural damage to residential, commercial and government buildings was observed (Earthquake Engineering Research Institute [EERI], 2005; Mid-America Earthquake [MAE] Center, 2005; U.S. Geological Survey [USGS]/EERI, 2010). The damage was attributed largely to lack of earthquake-resistant design, poor standard of construction and inferior quality of building materials. In majority of the collapsed or damaged structures, structural types, member dimensions and detailing practices (insufficient lap length, improper lap location and lack of confinement in columns etc) were found inadequate to resist forces imposed by these earthquakes. The 2011 off The Pacific Coast of Tohoku (Japan) earthquake is a modern day example of large scale devastation to a highly industrial nation in which building and infrastructure is well designed and constructed. Although, majority of causalities and large scale destruction of infrastructure was caused by ensuing tsunami, limited damage to the buildings due to ground shaking was reported (Pacific Earthquake Engineering Research Center [PEER]/EERI/Geotechnical Extreme-Event Reconnaissance [GEER]/Tsunami Field Investigation Team, 2011; Takewaki et al. 2011). However, extensive and severe structural damage was observed in older residential and commercial buildings that were constructed prior to 1978 code revision of Japan, whereas modern structures built to withstand seismic demands did not sustain any substantial and widespread damage (Aydan \& Tano, 2011). 
The existing reinforced concrete buildings with deficient seismic design can, however, be retrofitted to enhance their performance during future earthquakes. The need to assess their vulnerability to earthquake damage, and suggest desired level of retrofit, requires evaluation of their expected behavior in terms of strength and deformation capacity. In addition to the retrofitting requirements, there may be many situations where structures are required to be analyzed accurately to evaluate their structural responses. For example, in performance- and displacement-based design philosophy (Priestley et al, 2007, Structural Engineers Association of California [SEAOC], 2002), important existing buildings and planned future structures may need to be evaluated to determine their maximum load carrying capacity, ultimate deformation capacity, progression of the damage, and collapse mechanism. However, a realistic seismic damage analysis, in pre- or post-earthquake scenario, requires development of analytical models to accurately predict non-linear structural behavior during the seismic event (Mergos \& Kappos, 2010).

The expected behavior of a structure can be evaluated by determining load-deformation responses of the concrete elements, such as beams, columns and shear walls, considering all potential failure mechanisms associated with axial, flexure and shear behavior. The pattern of damage observed during past earthquakes suggests that columns are the most critical elements that sustain damage and lead the potential building failure. Hence, understanding of their response to applied seismic loads is vital for overall assessment of the structural performance. This paper presents a procedure for response estimation of reinforced concrete columns subjected to lateral loads, with focus on modeling columns commonly found in the older existing buildings. Traditionally, these columns have insufficient and widely spaced transverse reinforcement and non-seismic details such as 90-degree end hooks and splicing of the longitudinal bars in the regions experiencing largest inelastic deformations near column ends. Due to such deficiencies, columns may not have sufficient shear strength to develop plastic hinges at the ends. Also, wide spacing of column ties does not provide good confinement to the core concrete resulting in non-ductile behavior and sudden brittle failure. Although, this study focuses on modeling columns with poor seismic details, the proposed analytical procedure is equally applicable to predict structural response of the columns designed to meet the requirements of modern seismic codes.

\section{Research background and overview}

When a typical fixed ended reinforced concrete column is subjected to the lateral loads at its ends, it undergoes total lateral deformation that is mainly comprised of three components due to flexure, reinforcement slip and shear mechanisms (Setzler \& Sezen, 2008; Sezen \& Moehle, 2004) as shown in Figure 1.
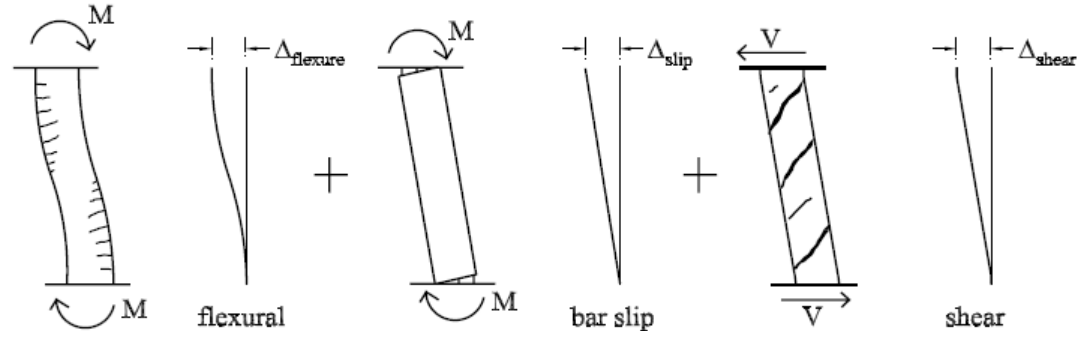

Fig. 1. Components of the total lateral deformation in a fixed ended column 
For a column whose behavior is dominated by flexure, issues regarding its performance evaluation have been studied well and current design procedures for strength estimation are generally considered well established. Among available approaches, most of which are either based on lumped plasticity models or distributed nonlinearity models, fiber models are considered advanced analytical procedures that can conveniently be employed for evaluating structural response. It must however be noted that fiber models are appropriate tools for analyzing flexural performance only and behavior of the columns dominated by shear related mechanisms can not be simulated.

For evaluating shear response of structural elements, such as beams and columns, many analytical models and theories have been presented in the past. Some of the most commonly used approaches are strut and tie models (Mörsh, 1902; Ritter, 1899; Schlaich et al., 1987) and empirical formulations/rational theories based on experimental observations such as Arakawa equation (Arakawa, 1970), Modified Compression Field Theory (MCFT) (Vecchio \& Collins, 1986) and Disturbed Stress Field Model (DSFM) (Vecchio, 2000). These approaches are fundamentally different in their theoretical modeling and conceptual development. Their applicability to structural members, computational demand and accuracy also vary in wide range from one approach to the other. Hence, accurate modeling of the shear behavior in beams and columns still remains elusive. MCFT is a powerful tool to model the response of reinforced concrete elements subjected to in-plane shear and normal stresses. However, in order to evaluate flexure-shear response of the reinforced concrete columns by MCFT, the member needs to be discretized into large number of biaxially stressed elements and analyzed using nonlinear finite element procedure (Vecchio, 1989). Vecchio and Collins (Vecchio \& Collins, 1988) extended concept of MCFT to fiber model approach for response estimation of reinforced concrete beams loaded in combined axial, shear and flexural forces. In this approach, concrete fibers are treated as biaxially stressed elements in the cross section and analyzed for in-plane stress field based on MCFT. Later, this approach was improved for accurate determination of shear stress distribution on the cross section and advanced formulations were implemented successfully into a non-linear section analysis computer program called Response-2000 (Bentz, 2000). The application of the MCFT in finite element approach or sectional analysis approach yields reliable flexureshear response, but results in fastidious computations which are not simple for practical applications.

Total lateral deformation of a concrete column is mainly comprised of the flexure and shear components. These mechanisms interact with each other and corresponding deformations do not occur independently. For example, in the web of a reinforced concrete column, axial strain due to flexural mechanism will increase principal tensile strain and width of the shear crack resulting in lower shear capacity of the element. On the other hand, it has been established by experimental evidence that principal compressive stress in the concrete is function of principal compressive strain as well as of principal tensile strain (Vecchio \& Collins, 1986). Compressive strength and stiffness of concrete decrease as tensile strains increase. The concrete in the web of laterally loaded element is subjected to shear stresses in addition to the normal stresses due to axial load and flexure. As the shear stresses increase, principal tensile strains increase which will decrease compressive strength of the concrete resulting in lower flexural strength of the element. 
Therefore, any numerical procedure that aims to model overall lateral load-displacement relationship must take the interaction of flexural and shear mechanisms into account. Recently, Mostafaei and Kabeyasawa (Mostafaei \& Kabeyasawa, 2007) presented AxialShear-Flexural Interaction (ASFI) approach for the displacement-based analysis of reinforced concrete elements such as beams, columns and shear walls by considering interaction between axial, shear and flexural mechanisms. This macro-model based approach consists of two models evaluating axial-flexural and axial-shear responses simultaneously to obtain total response of elements subjected to axial, flexural and shear loads. In this approach, axial-flexural behavior is simulated by employing conventional section analysis or fiber model whereas axial-shear response is determined through MCFT by considering one integration point in the in-plane stress conditions. The axial-flexural and axial-shear mechanisms are coupled in average stress-strain field considering axial deformation interaction and softening of concrete compression strength while satisfying compatibility and equilibrium conditions. Although, ASFI approach reduces computational demand considerably as compared to other models implementing MCFT into finite element analysis approach or sectional analysis approach, computational process is still intense and complicated due to coupling of the axial-flexure and axial-shear mechanisms and requires a deliberate iterative scheme at each loading step. However, few concepts from ASFI approach are utilized in the model proposed in this study.

Few studies in the recent past have also addressed the issues of stiffness degradation and strength deterioration in the reinforced concrete elements dominated by shear or shearflexure behaviors. These studies represent advanced formulations for fiber-based element (Ceresa et al., 2007, 2009; Chao \& Loh, 2007; Mullapudi \& Ayoub, 2008, 2010; Xu \& Zhang, 2011; Zhang \& Xu, 2010) and Macro-element model (Mergos \& Kappos, 2008, 2010) and consider interaction between inelastic shear and nonlinear flexural behaviors with different conceptual backgrounds, solution strategies and implementation complexities. A state-of-art review is presented on fiber elements with focus on concentrated plastic-hinge type model that can be implemented in displacement-based finite element programs (Ceresa et al., 2007).

Currently available studies for response estimation of non-ductile reinforced concrete columns show that the approaches that can predict structural behavior with good accuracy employ complicated and computation-intensive procedures that may not be amenable and are difficult to implement. As a result, many approaches try to simplify the process by making simplifying assumptions but in most cases this is done at the cost of accuracy. A suitable procedure is proposed here to address critical modeling issues while predicting the response accurately and keeping overall computational process simple with easy implementation. The authors believe that the proposed model can effectively be employed to predict the strength and total lateral displacement capacity, considering the deformation components due to flexure, shear and reinforcement slip. Implementation of the proposed procedure results in satisfactory response envelope curves which can be used for development of cyclic response models.

\section{The proposed analytical procedure for response estimation of columns}

Flexural and shear deformations in the proposed model are calculated independently while considering the interaction between these mechanisms and then combined together depending upon dominant failure mode. The flexural deformations are determined through 
fiber section model considering shear effects by employing compressive constitutive law for cracked concrete. Shear deformations are calculated by combination of MCFT (Vecchio \& Collins, 1986) and shear response envelope by Sezen (Sezen, 2008), while considering effect of axial strains due to flexure on shear mechanism. Lateral deformation component due to reinforcement slip in beam-column joint regions is determined separately and added to the flexural and shear deformation components to obtain total response. The interaction between flexure and shear mechanisms allows for accurate response estimation while decoupled flexural analysis minimizes complexity of calculations and makes the analysis process relatively simple and easy. In addition, buckling of compression bars under large compressive strains is also incorporated in the analysis by employing separate stress-strain relationships for reinforcing steel in compression. The effects of concrete tension strength and softening of cracked concrete in compression are also considered. The details of the components deformation models and total deformation model are presented in the following sub-sections.

\subsection{Flexural analysis and deformations}

Flexural deformations in the proposed procedure are determined from fiber section analysis in one-dimensional stress field. For the reinforced concrete elements subjected to bending moment and axial load, such as beams or columns, fiber model approach is usually handy and accurate approach if actual stress distribution across the depth of the cross-section is considered. The reliability of the analysis is also directly related to the ability of the constitutive material models to accurately simulate material behavior and level of simplifying assumptions during the analysis. In this approach, a reinforced concrete crosssection is discretized into finite number of concrete and steel fibers. Each of the fibers is idealized as a uniaxial element with its unique stress-strain relationship. Bernoulli's principle, that plane section before bending remains plane after bending, is the main hypothesis in the analysis and implies that the longitudinal strain in concrete and steel at any point in the cross section is proportional to its distance from neutral axis resulting in linear strain distribution. Based upon the resulting strain profile, stress distribution for concrete and reinforcing steel can be determined in accordance with their respective stressstrain relationships. By satisfying equilibrium equations at the cross section, the moment capacity of the section is determined. The process is repeated number of times by incrementing longitudinal stain until either the concrete or steel fails as per defined failure criterion.

In conventional flexural section analysis, the concrete behavior is simulated by its response usually derived from standard cylinder test where it is subjected to uniaxial compression. The strain conditions for the concrete in the web of a laterally loaded reinforced concrete beam or column are significantly different from those in a cylinder test. The concrete in a cylinder test is subjected to only small tensile strains primarily due to Poisson's effect, whereas, the concrete in the web experience shear stresses in addition to the normal stresses due to axial load and flexure. Due to applied shear stresses, concrete in the web cracks diagonally in the direction normal to principal tensile strain. As mentioned earlier, experimental evidence has shown that that principal compressive stress in the concrete is not only the function of principal compressive strain but is also affected by the coexisting principal tensile strain in a way that compressive strength and stiffness of the concrete 
decrease as tensile strains increase (Vecchio \& Collins, 1986). This implies that the concrete subjected to combined normal compressive and shear stresses is weaker in compression than the concrete subjected to normal compressive stresses only. Hence, the concrete in the web of a laterally loaded column must exhibit weaker and softer response as compared to the concrete subjected to uniaxial compression in cylinder test. The behavior of the cracked concrete in the manner explained above is called compression-softening and is illustrated in Figure 2. In this figure, $f_{c}^{\prime}$ is compressive strength of the concrete, $f_{c 2}$ is principal compressive stress in the concrete and $\varepsilon_{c 2}$ is principal compressive strain in the concrete.

The effect of shear stress on degrading compressive strength of the concrete can be taken into account by considering compressive stress-strain relationships of diagonally cracked concrete in flexural section analysis instead of employing conventional constitutive relationship for uniaxially compressed concrete. This can be done by softening the response of concrete in uniaxial compression by a factor which decreases as shear deformations increase. This factor, known as compression softening factor $\beta$, is function of principal tensile strain in the concrete and is defined as following (Vecchio \& Collins, 1986).

$$
\beta=\frac{1}{0.8-0.34 \frac{\varepsilon_{c 1}}{\varepsilon_{c o}}} \leq 1.0
$$

where $\varepsilon_{c o}$ is concrete strain corresponding maximum concrete cylinder strength and $\varepsilon_{c 1}$ is principal tensile strain in the concrete which can be determined through in-plane shear analysis of the flexural element. The procedure for determining principal tensile strain in the concrete and compression softening factor is explained in the subsequent section.

In addition to considering cracked concrete behavior in the fiber model, enhancement in the strength and ductility of the concrete due to confinement and contribution of the concrete tensile properties to section moment capacity must also be considered in the analysis. For determining realistic moment capacity and analyzing the buckling of the longitudinal bars under excessive compressive strains, confined core concrete and unconfined cover concrete are modeled separately with their respective stress-strain relationships.

Fiber model analysis results in a moment-curvature relationship for given geometric and material properties, reinforcement details and applied axial load for the cross-section being analyzed. From here, lateral load $V$ corresponding to respective moment capacity, resulting average shear stress from flexural analysis $\tau_{f}$ and maximum lateral force sustainable by the column can be calculated with the help of following equations.

$$
V=\frac{M}{a} \quad \tau_{f}=\frac{V}{b d} \quad V_{p}=\frac{M_{p}}{a}
$$

where, $M$ is the flexural section moment capacity at any load level, $b$ is width of the section, $d$ is the effective depth of the section, $a$ is the shear span equal to cantilever column length and one half of the length a fixed ended column, and $M_{p}$ is maximum moment capacity from flexural section analysis.

Flexure deformations are calculated with the help of plastic hinge model in which elastic and inelastic curvatures are idealized separately. In this model, a linear curvature 
distribution is assumed in the elastic range over the length of the column, and the inelastic curvatures are lumped at the column end over the plastic hinge length. The conceptual illustration of the plastic hinge model for a cantilever column is presented in Figure 3. Hence, lateral displacement due to flexure $\Delta_{f}$ can be calculated by integrating curvature over the length of the column as per Equation 3.

$$
\Delta_{f}=\int_{0}^{a} \phi(x) x d x
$$

where $\phi(x)$ is section curvature at distance $x$ measured along column axis, and $\phi_{y}$ is curvature at yield point. The plastic hinge length $L_{p}$ is taken as one-half of the section depth $h$.

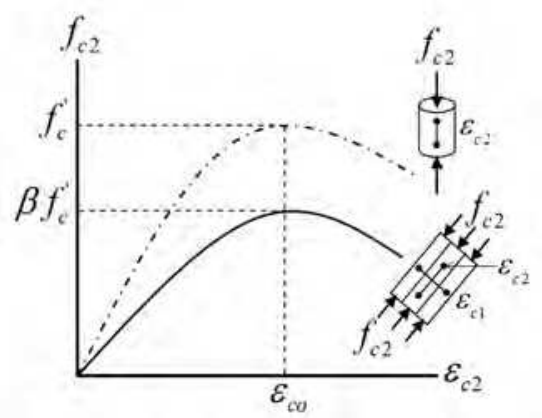

Fig. 2. Behavior of the cracked concrete in compression

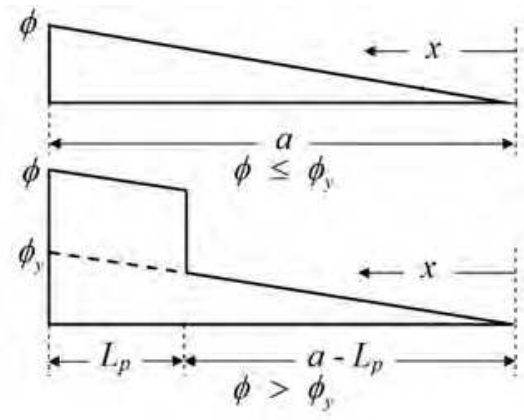

Fig. 3. Plastic hinge model for calculating flexural displacements

\subsection{Reinforcement slip deformations}

When a reinforced concrete column is subjected to bending moment, strain accumulates in the embedded length of the tensile reinforcing bars. This causes the bars to extend or slip relative to the anchoring concrete at column fixed end(s). The extension is commonly known as reinforcement slip and leads to rigid-body rotation of the column, as shown in Figur 1. This results in an additional lateral displacement component that can be as large as 25 to 40 
$\%$ of the total lateral displacement (Sezen, 2002). Flexural deformations determined from conventional fiber section analysis (moment-curvature analysis) do not account for lateral deformations caused by reinforcement slip at column ends. Therefore, these deformations must be calculated separately and added to the other deformation components due to flexure and shear to calculate the total lateral displacement.

In this study, lateral displacement due to reinforcement slip is calculated using the model illustrated in Figure 4 (Sezen \& Setzler, 2008).
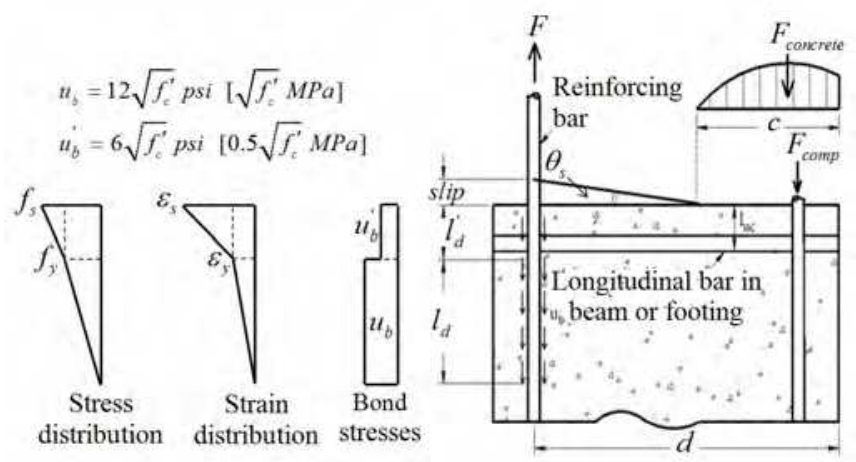

Fig. 4. Reinforcement slip model (Sezen \& Setzler, 2008)

The model approximates the bond stress as bi-uniform function with different values for elastic and inelastic steel behaviors. The bond stress in the elastic and inelastic range is taken as $u_{b}=12 \sqrt{f_{c}^{\prime}} p s i\left(1 \sqrt{f_{c}^{\prime}} M P a\right)$ and $u_{b}^{\prime}=6 \sqrt{f_{c}^{\prime}} p s i\left(0.5 \sqrt{f_{c}^{\prime}} M P a\right)$, respectively, where $f_{c}^{\prime}$ is concrete compressive strength. Slip $s$ at the loaded end of the reinforcing bar can be calculated by integrating bi-linear strain distribution $\varepsilon_{s}(x)$ over the development length as follows.

$$
S=\int_{0}^{l_{d}+l_{d}^{\prime}} \varepsilon_{s}(x) d x
$$

where $l_{d}=\frac{f_{s} d_{b}}{4 u_{b}}$ and $l_{d}^{\prime}=\frac{\left(f_{s}-f_{y}\right) d_{b}}{4 u_{b}^{\prime}}$ are development lengths for the elastic and inelastic portion of the bar, respectively. Hence, integrating Equation 4, extension or slip of the reinforcing bars is

$$
s= \begin{cases}\frac{\varepsilon_{s} l_{d}}{2}=\frac{\varepsilon_{s} f_{s} d_{b}}{8 u_{b}} & \text { for } \varepsilon_{s} \leq \varepsilon_{y} \\ \frac{\varepsilon_{y} l_{d}}{2}+\frac{\left(\varepsilon_{s}+\varepsilon_{y}\right) l_{d}^{\prime}}{2}=\frac{\varepsilon_{y} f_{y} d_{b}}{8 u_{b}}+\frac{\left(\varepsilon_{s}+\varepsilon_{y}\right)\left(f_{s}-f_{y}\right) d_{b}}{8 u_{b}^{\prime}} & \text { for } \varepsilon_{s}>\varepsilon_{y}\end{cases}
$$

where $\varepsilon_{s}$ is the strain at loaded end of the bar, $\varepsilon_{y}$ is steel yield strain, $f_{s}$ is stress at loaded end of the bar, $f_{y}$ is steel yield stress, and $d_{b}$ is diameter of the longitudinal bar. The 
reinforcement slip is assumed to occur in tension bars only and cause the rotation about the neutral axis as shown in Figure 4. Rotation caused due to reinforcement slip can be calculated as,

$$
\theta_{s}=\frac{s}{d-c}
$$

where $d$ and $c$ are the distances from the extreme compression fiber to the centroid of the tension steel and neutral axis, respectively. The lateral displacement due to slip at free end of a cantilever column can be calculated as the product of slip rotation $\theta_{s}$ and length of the column $L$ as,

$$
\Delta_{S}=\theta_{s} L
$$

\subsection{Shear deformations}

Shear deformations in reinforced concrete members have traditionally been ignored in design and research due to lack of their complete understanding and being difficult to measure, independent of other deformation components, in an experimental set up or a real structure. For a well designed reinforced concrete column, shear deformations are small as compared to the flexural deformations and are often less than 10 percent of total deformations. Contrary, for a reinforced concrete column not designed according to stricter seismic design provisions, shear behavior could be the governing failure criterion. Shear deformations in such shear critical reinforced concrete column could contribute large percentage towards total deformations and hence can not be ignored if an accurate analysis of deformation capacity is required.

Shear deformations in the proposed model are calculated using a combination of MCFT (Vecchio \& Collins, 1986) and post-peak shear response envelope (Patwardhan, 2005; Sezen, 2008). In this model, pre-peak non-linear shear force-shear deformation response is obtained from in-plane analysis of the shear element based on MCFT while considering the interaction of the axial strain (Mostafaei \& Kabeyasawa, 2007). Axial strain obtained from flexural section analysis is incorporated into the total axial strain of the shear element to include the effect of flexural behavior on shear response. After the peak strength has reached, shear strength is first assumed to remain constant at its peak value until the onset of the shear strength degradation and then declines linearly with increasing shear deformations to the point of axial load failure (Figure 5). At the point of axial load failure, lateral strength is assumed zero. The peak strength $V_{\text {peak }}$ in the proposed shear response model refers to the point where response estimation by MCFT terminates either due to shear failure or reaching the load step corresponding to the peak flexural strength prior to experiencing shear failure. Hence, the peak strength $V_{\text {peak }}$ is the minimum of the shear strength of the column $V_{n}$ and shear force corresponding to the maximum moment that can be carried by the section $V_{p}$.

Shear displacements at the onset of shear degradation $\Delta_{v, u}$ can be calculated as follows (Patwardhan, 2005; Sezen, 2008).

$$
\Delta_{v, u}=\left(4-12 \frac{v_{n}}{f_{c}^{\prime}}\right) \Delta_{v, n}
$$




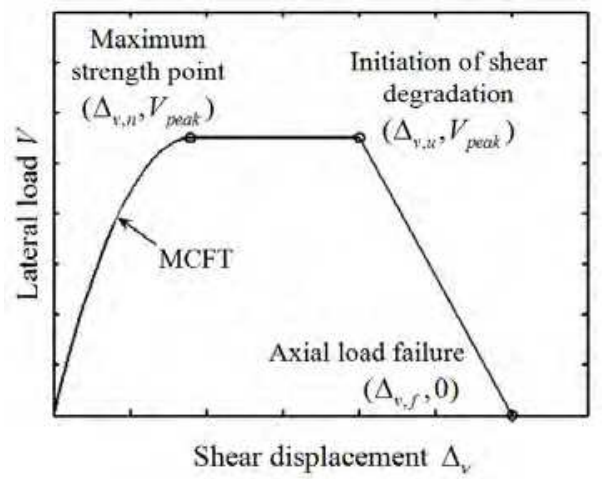

Fig. 5. Shear response model

where $v_{n}=\frac{V_{\text {peak }}}{b d}$ is the shear stress at peak strength, $f_{c}^{\prime}$ is the concrete compressive strength, and $\Delta_{v, n}$ is the shear displacement corresponding to the peak strength as determined from MCFT analysis. The shear displacement at axial load failure $\Delta_{v, f}$ is calculated as,

$$
\Delta_{v, f}=\Delta_{A L F}-\Delta_{f, f}-\Delta_{s, f} \geq \Delta_{v, u}
$$

where $\Delta_{A L F}$ is the total displacement at axial load failure, $\Delta_{f, f}$ and $\Delta_{s, f}$ are the flexural and slip displacement at the point of axial load failure, respectively. The total displacement at axial load failure is determined by the expression based on a shear friction model and an idealized shear failure plane (Elwood \& Moehle, 2005).

$$
\Delta_{A L F}=\frac{0.04 L\left(1+\tan ^{2} \theta\right)}{\left(\tan \theta+P\left(\frac{s_{h}}{A_{s v} f_{y v} d_{c} \tan \theta}\right)\right)}
$$

where $\theta$ is the angle of the shear crack, $P$ is the axial load, $A_{s v}$ is the area of transverse steel with yield strength $f_{y v}$ at spacing $s_{h}$, and $d_{c}$ is the depth of the core concrete measured to the centerlines of the transverse reinforcement. In the derivation, $\theta$ is assumed to be 65 degrees. The values of $\Delta_{f, f}$ and $\Delta_{s, f}$ in Equation 9 are determined according to the expected failure mode and classification of the column into categories as explained in subsequent subsection.

\subsection{Total lateral response}

In order to model the response of a column subjected to lateral loading, three deformation components should be combined together considering their interconnectedness. In this study, total column lateral response is modeled as a set of three springs in series; each spring representing lateral displacement component due to flexure, bar slip and shear. Each 
spring is subjected to same force and total displacement is sum of responses of each spring. The pre-peak total response is obtained by simply adding deformation components due to flexure, bar slip and shear mechanism as described above. After reaching the peak, the mechanism limiting the peak strength (flexure or shear) will dominate the behavior. The procedure for combining deformation components for post peak is explained below and the model is illustrated in Figure 6.

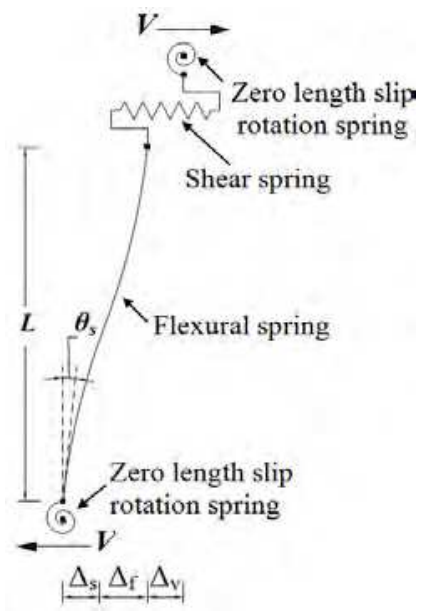

Fig. 6. Spring representation of total response model

For post-peak behavior, the column is classified into one of the five categories based on a comparison of its shear, yield and flexural strength and rules are specified for the combination of the deformation components for each category (Setzler \& Sezen, 2008). The yield strength $V_{y}$ is defined as the lateral load corresponding to the first yielding of the tension bars in the column and flexural strength $V_{p}$ is the lateral load corresponding to the peak moment calculated from flexural analysis. Both of these loads are calculated from moment-curvature analysis of the fiber model as explained above. The shear strength $V_{n}$ for the columns failing in shear prior to the reaching flexural strength or failing close to flexural strength is determined from the proposed shear model, where $V_{n}=V_{\text {peak }}$ as discussed above. For other columns where peak strength by the proposed shear model is close to the flexural strength, shear strength is calculated as a function of displacement ductility (Sezen \& Moehle, 2004).

$$
V_{n}=k\left(V_{c}+V_{s}\right)=k\left[\left(\frac{6 \sqrt{f_{c}^{\prime}}}{a / d} \sqrt{1+\frac{P}{6 \sqrt{f_{c}^{\prime}} A_{g}}}\right) 0.80 A_{g}+\frac{A_{s v} f_{y v} d}{s}\right]
$$

where $V_{c}$ is the concrete contribution to shear strength, $V_{s}$ is the steel contribution to shear strength, $A_{g}$ is gross cross-sectional area, $a / d$ is the aspect ratio and $k$ is a factor related to the displacement ductility which is the ratio of the maximum displacement to the yield displacement. The value for $k$ varies from 0.7 to 1.0 for displacement ductilites from less than 2 to grater than 6 respectively. In this study, the value for $\mathrm{k}$ is taken as 1.0 as classification of the columns is based on initial or low-ductility shear and flexural strengths. 
The classification system and rules governing the post peak response in each category are described below and are illustrated in Figure 7. Peak response of the column is limited by the smaller of the shear strength and flexural strength, however post-peak response is assumed to be governed by the limiting mechanism (i.e., flexure or shear).

\subsubsection{Category - I $\left(V_{n}<V_{y}\right)$}

In this category of the columns, shear strength is less than the yield strength and column fails in shear while the flexural behavior remains elastic. The deformation at peak strength (i.e., shear strength) is the sum of deformations in each spring at the peak strength. After the peak strength is reached, the shear behavior dominates the response. As the shear strength degrades, the flexure and slip springs unload along their initial responses. The post-peak deformation at any lateral load level is the sum of the post-peak shear deformation and the pre-peak flexural and slip deformations corresponding to that load.

\subsubsection{Category - II $\left(V_{y} \leq V_{n}<0.95 V_{p}\right)$}

The shear strength is less than flexural strength and column fails in shear, however inelastic flexural deformation occurring prior to shear failure affects the post-peak behavior. The deformation at peak strength is the sum of the deformations in each spring at the peak strength. Shear deformations continue to increase after the peak shear strength is reached, but the flexure and shear springs are locked at their peak strength values. Hence, post-peak deformations at any lateral load level is the sum of flexural and slip deformations at the peak strength and post-peak shear deformation at that load.

\subsubsection{Category - III $\left(0.95 V_{p} \leq V_{n} \leq 1.05 V_{p}\right)$}

The shear and flexural strengths are nearly identical. Shear and flexural failure are assumed to occur "simultaneously," and both mechanisms contribute to the post-peak behavior. The post-peak deformation at any lateral load level is the sum of the post-peak flexure, slip, and shear deformations corresponding to that load.

\subsubsection{Category - IV $\left(1.05 V_{p}<V_{n} \leq 1.4 V_{p}\right)$}

The shear strength is greater than the flexural strength and the column may potentially fail in the flexure, however large shear deformations affect the post-peak behavior and shear failure may occur as the displacements increase. The deformation at peak strength is the sum of the deformations in each spring at the peak strength. After the peak strength is reached, flexural and slip deformations continue to increase according to their models, but the shear spring is locked at its value at peak strength. The post-peak deformation at any lateral load level is the sum of the post peak flexural and slip deformations corresponding to that load and the shear deformation at peak strength.

\subsubsection{Category - V $\left(V_{n}>1.4 V_{p}\right)$}

The shear strength is much greater than the flexural strength and column fails in flexure while shear behavior remains elastic. The peak strength of the column is the flexural strength calculated from the flexure model. If the column strength degrades, flexural and 
slip deformations continue to increase according to their models, while the shear spring unloads with an unloading stiffness equal to its initial stiffness. The post-peak deformation at any lateral load level is the sum of the post-peak flexural and slip deformations and the pre-peak shear deformation corresponding to that load.

For category-I columns, $\Delta_{f, f}$ and $\Delta_{s, f}$ values to be used in Equation 9 are assumed zero.

For the category-II columns, shear strength is lesser than flexural strength and these values are taken as the flexural and slip deformations at the load equal to the shear strength of the columns. For categories III, IV, and V specimens, $\Delta_{f, f}$ and $\Delta_{s, f}$ are the maximum calculated flexural and slip deformations.
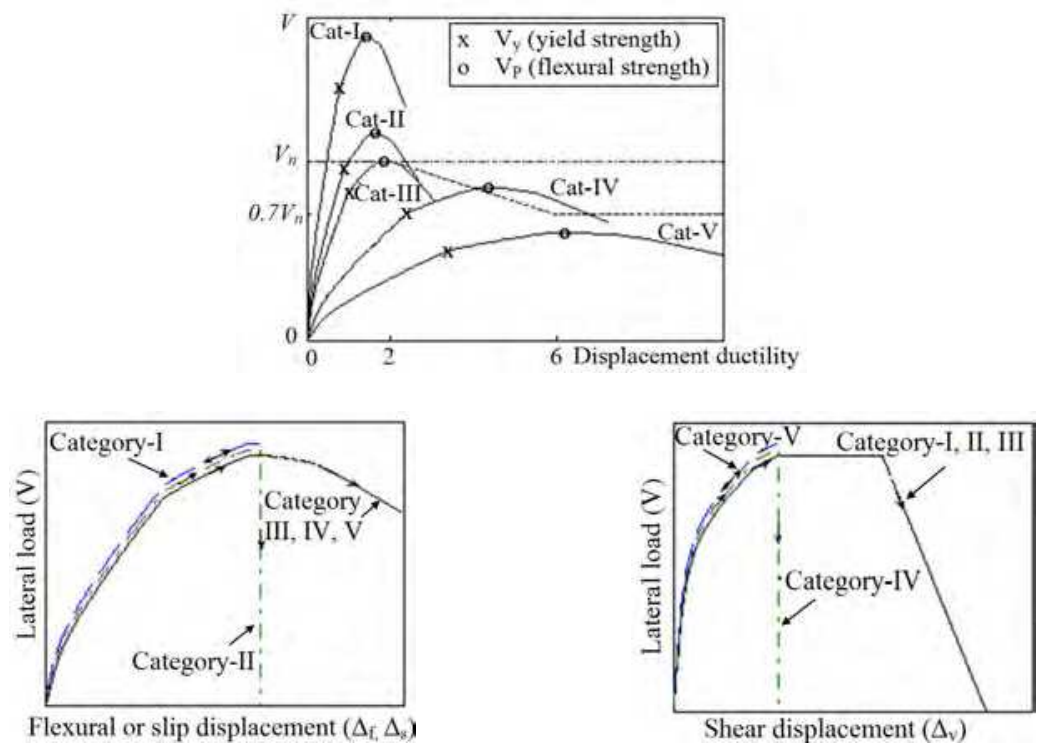

Fig. 7. Classification of columns into categories and rules governing combination of the deformation components (Setzler \& Sezen, 2008)

\section{Interaction between flexure and shear mechanisms}

When a fixed-ended reinforced concrete column is subjected to lateral loading, such as during an earthquake, flexural and shear mechanisms interact with each other and affect overall response of the column. The interaction between flexural and shear deformations in the proposed analytical procedure is based on the ASFI approach (Mostafaei \& Kabeyasawa, 2007). Interaction methodology in ASFI approach couples axial-flexure and axial-shear models with each other. Both mechanisms have to be evaluated simultaneously which makes ASFI approach relatively complicated and computationally intensive. The computational effort can be reduced significantly, if the analyses for flexural and shear behavior can be performed independently. Therefore, in the proposed procedure, the interaction of the shear deformations on flexural performance, and vice versa, are considered in a simplified manner that allows easy implementation and decoupled flexural and shear response evaluations. 


\subsection{Interaction of concrete compression softening}

Cracked concrete behavior is considered in flexural section analysis to represent degradation in compressive strength of the concrete due to applied shear stresses. This requires determination of the compression softening factor $\beta$ to lower concrete stresses in uniaxial compression (Figure 2). The procedure for determining compression softening factor is adopted from the recently developed model called Uniaxial-Shear-Flexure Model (USFM) (Mostafaei \& Vecchio, 2008). This is an approximate approach for response estimation of reinforced concrete elements which is derived after simplifying ASFI approach. USFM employs few fundamental equations of the MCFT and two assumptions on average principal compressive strain and average centroidal axial strain of the element to determine average principal tensile strain. The details of formulation, implementation and verification of USFM approach can be found in (Mostafaei \& Vecchio, 2008).

Compression softening factor $\beta$, as defined in Equation 1, is a function of concrete principal tensile strain $\varepsilon_{c 1}$ of the element being analyzed. The procedure to approximately determine principal tensile strain and subsequently compression softening factor for a fixed ended column subjected to in-plane lateral load is illustrated in Figure 8. For an element considered between inflection point and one of the end sections of the column, $\varepsilon_{c 1}$ can be determined from the following MCFT equation.

$$
\varepsilon_{c 1}=\varepsilon_{x}+\varepsilon_{y v}-\varepsilon_{c 2}
$$

where, $\varepsilon_{x}$ is average axial strain at the centroid for the element and is obtained by averaging the values of centroidal axial stain at one of the end section $\varepsilon_{0}$ and axial strain of the inflection point $\varepsilon_{x a}$. Likewise $\varepsilon_{c 2}$ is average concrete principal compressive strain for the element. Its value, as per USFM assumption (Mostafaei \& Vecchio, 2008), can be taken as the average of the uniaxial concrete compressive strain corresponding to resultant compressive force of the stress block at end section $\varepsilon_{c}$ and axial strain at the inflection point $\varepsilon_{x a}$. Hence,

$$
\varepsilon_{x}=\frac{\left(\varepsilon_{o}+\varepsilon_{x a}\right)}{2} \quad \varepsilon_{c 2}=\frac{\left(\varepsilon_{c}+\varepsilon_{x a}\right)}{2}
$$

The other unknown quantity in Equation 12, strain of the transverse reinforcement $\varepsilon_{y v}$, can be determined from the following MCFT based relationship.

$$
\varepsilon_{y v}=\sqrt{b^{2}+c}-b
$$

where,

$$
b=\frac{f_{c 1}}{2 \rho_{y} E_{s y}}-\frac{\varepsilon_{c 2}}{2}, c=\frac{\left(\varepsilon_{x}-\varepsilon_{c 2}\right)\left(f_{c 1}-f_{c x}\right)+f_{c 1} \varepsilon_{c 2}}{\rho_{y} E_{s y}}, f_{c x}=f_{x}-\rho_{x} f_{s x}
$$

where $\rho_{y}$ is transverse reinforcement ratio, $E_{s y}$ is modulus of elasticity of transverse reinforcement, $f_{c x}$ is concrete stress in longitudinal axis of the column, $f_{x}$ is applied axial stress, $\rho_{x}$ is longitudinal reinforcement ratio, $f_{s x}$ is longitudinal steel stress obtained from 
section analysis based on average centroidal strain, $f_{c 1}=0.145 \sqrt{f_{c}^{\prime}}$ is concrete principal tensile stress (in $\mathrm{MPa}$ ), $\varepsilon_{x}$ is normal strain at the centroid and $\varepsilon_{c 2}$ is average concrete principal compressive strains, both determined from Equation 13.

After calculating concrete principal tensile strain $\varepsilon_{c 1}$ from Equation 12, compression softening factor $\beta$ is determined from Equation 1 for a given curvature. This is the estimated value of $\beta$ which is employed in fiber model analysis to lower concrete stresses. In the proposed procedure, compression softening factor determined with the help of above mentioned procedure is employed till peak flexural strength and then a constant value equal to the last lowest is used for post-peak flexural analysis.

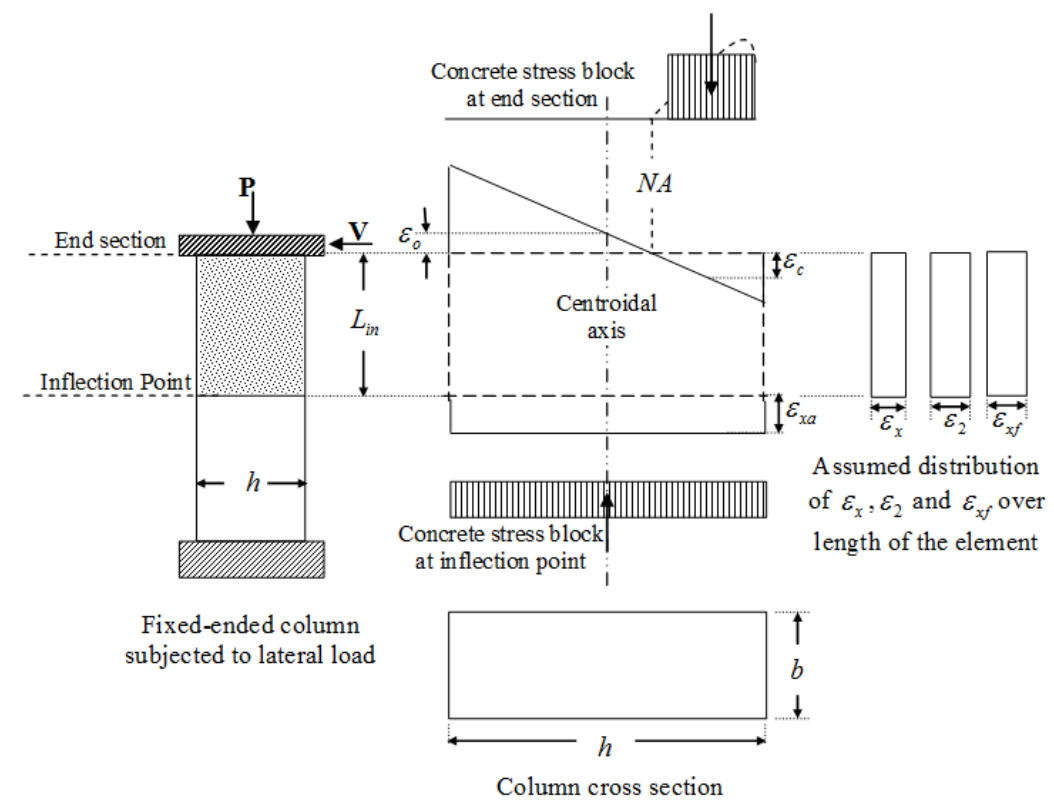

Fig. 8. Interaction of compression softening and axial strains (Mostafaei \& Kabeyasawa, 2007; Mostafaei \& Vecchio, 2008).

\subsection{Interaction of axial strains}

The effect of flexural deformations on shear behavior is considered by incorporating axial strain and shear stress due to flexure into in-plane analysis of the shear element based on axial strain interaction methodology of ASFI approach (Mostafaei \& Kabeyasawa, 2007) and equilibrium of shear stresses in flexural and shear mechanisms. In this procedure, interaction of axial strain is taken into account by adding flexibility component of axial deformation due to flexure to the corresponding flexibility component of axial-shear model. By employing flexural shear stress to in-plane stress-strain relationship of the shear element, shear deformations are determined. The procedure for axial deformation interaction and determination of shear strain is described here for a fixed ended column subjected to lateral load. 
The length of the column between inflection point and one of the end sections is considered as a shear element subjected to constant normal stress due to applied axial load and average shear stresses due to applied lateral load. Performing flexural analysis on fiber model of the end section and inflection point, average centroidal axial strain due to flexure $\varepsilon_{x f}$ (Figure 8) and corresponding flexibility component $f_{x f}$ can be determined with the help of following ASFI equations (Mostafaei \& Kabeyasawa, 2007).

$$
\varepsilon_{x f}=\frac{\left(\varepsilon_{o}-\varepsilon_{x a}\right)}{2}, f_{x f}=\frac{\varepsilon_{x f}}{\sigma_{x}}, \sigma_{x}=\frac{P}{b d}
$$

where, $\sigma_{x}$ is applied axial stress in longitudinal direction of the column and can be determined by dividing the applied axial load $P$ by the effective area of the cross section.

A stress-strain relationship in terms of flexibility matrix for an in plane shear element (axialshear model) can be defined as,

$$
\left(\begin{array}{lll}
f_{11} & f_{12} & f_{13} \\
f_{21} & f_{22} & f_{23} \\
f_{31} & f_{32} & f_{33}
\end{array}\right)\left\{\begin{array}{l}
\sigma_{x} \\
\sigma_{y} \\
\tau_{x y}
\end{array}\right\}=\left\{\begin{array}{l}
\varepsilon_{x} \\
\varepsilon_{y} \\
\gamma_{x y}
\end{array}\right\}
$$

where $f_{i j}(i, j=1,2,3)$ are flexibility components of in plane shear model, $\sigma_{x}$ is normal applied stresses in longitudinal direction, $\sigma_{y}$ is normal stress in transverse direction, $\tau_{x y}$ is shear stress, $\varepsilon_{x}$ is normal strain in axial direction, $\varepsilon_{y}$ is normal strain in transverse direction, and $\gamma_{x y}$ is shear strain.

Axial strain due to flexure $\varepsilon_{x f}$ can be taken into account in the axial-shear model by adding flexibility component obtained from Equation 16 into Equation 17.

$$
\left(\begin{array}{ccc}
\left(f_{11}+f_{x f}\right) & f_{12} & f_{13} \\
f_{21} & f_{22} & f_{23} \\
f_{31} & f_{32} & f_{33}
\end{array}\right)\left\{\begin{array}{c}
\sigma_{x} \\
\sigma_{y} \\
\tau_{x y}
\end{array}\right\}=\left\{\begin{array}{c}
\varepsilon_{x}+\varepsilon_{x f} \\
\varepsilon_{y} \\
\gamma_{x y}
\end{array}\right\}
$$

In Equation 18, stresses in transverse direction (clamping stresses) are zero due to inexistence of lateral external force along the column, i.e., $\sigma_{y}=0$. In addition, the applied shear stress $\tau_{x y}$ of the element is taken from flexural section analysis (Equation 2) as $\tau_{x y}=\tau_{f}$. In Equation 18, knowing the applied stresses, corresponding strains can be calculated. The flexibility matrix is obtained by inverting material stiffness matrix of the shear element formulated using secant stiffness methodology of the MCFT approach (Vecchio \& Collins, 1986).

\section{Buckling of compression bars}

Longitudinal reinforcing bars in columns may experience inelastic axial compression under severe loading and exhibit large lateral deformation known as buckling. The behavior in the compressive face of a concrete member at overload depends on a variety of factors such as, size and shape of the cross-section, the amount of longitudinal compression steel, the amount of transverse reinforcement providing confinement to the section, thickness of the 
cover concrete, and stress-strain properties for the steel and concrete (Potger et al., 2001). The tendency for the compressively loaded steel bars to buckle and deflect outwards is initially resisted by the lateral restraint provided by the surrounding cover concrete as well as the transverse steel ties. As the compressive loads increase and approach the section capacity, the concrete surrounding the compressive bars carries large longitudinal compressive stress, and eventually becomes prone to longitudinal cracking, and spalling. After the cover concrete spalls off, ties restrain lateral movement and buckling.

In this study, compression steel stresses were reduced to account for buckling using the model shown in Figure 9. According to this model, compression stresses in longitudinal bars start to decrease when unconfined cover concrete starts to spall. When this happens, corresponding strain in the relevant steel layer can be calculated from flexural strain distribution across the cross section depth. This strain is $\varepsilon_{s p}$ as shown in the figure. This point can fall anywhere on typical stress-strain relationship for steel depending upon the level of flexural strain. Steel stresses follow their usual constitutive stress-strain relationship until strain reaches this limit. Then compression stresses in reinforcement follow new path defined by a line joining peak stress point to residual strength point having a slope $m$, which is calculated from following relationship (Inoue \& Shimizu, 1988).

$$
m=100 \varepsilon_{y x}\left(\frac{1}{\sqrt{1+500 \lambda^{2}}}-1\right) E_{s x} ; \lambda=\frac{\alpha s_{h}}{i_{r}}
$$

where, $\varepsilon_{y x}$ is yield strain of longitudinal bars, $E_{s x}$ is modulus of elasticity for longitudinal steel, $\alpha$ is 1.0 for corner bars and 0.5 for intermediate bars, $s_{h}$ is stirrup or tie spacing, and $i_{r}$ is radius of gyration of longitudinal bar.

Diameter of the longitudinal bar and spacing of the transverse reinforcement is important parameters that affect the buckling of the compression bars (Monti \& Nuti, 1992). Smaller diameter bars restrained by widely spaced ties are most likely to undergo lateral deformations and buckling much earlier during loading history than larger diameter bars confined by closely spaced transverse reinforcement. Therefore, in the proposed model, for tie spacing to bar diameter ratio $s_{h} / d_{b}$ of less than 5.00 , no buckling is considered and compressive behavior of the reinforcement is similar to its tensile behavior. For $s_{h} / d_{b}$ ratio above 11.00, the bars are considered to buckle as soon as reinforcement yields. For $s_{h} / d_{b}$ ratios between 5.00 and 11.00, post-buckling softening is considered soon after spalling of the cover concrete with the proposed model.

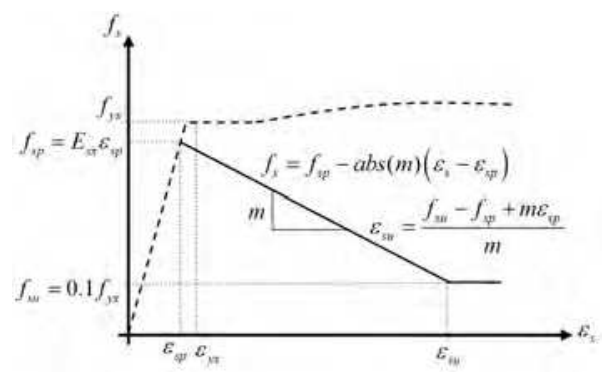

Fig. 9. Proposed compression bar buckling model 


\section{Analytical steps for implementation of the proposed procedure}

Total lateral displacement of a concrete column can be calculated under lateral loads. Note that the procedure can be used to model the response prior to peak strength (under increasing loads) and also beyond peak response (possible decreasing lateral loads due to strength and stiffness degradation). The major steps of the proposed procedure are to:

- Define uniaxial material properties for unconfined and confined concrete, and reinforcing steel. Include the effect of compression softening of concrete (Equation 1 and Figure 2). Consider the effect of compression bar buckling under large axial deformations (Equation 19 and Figure 9).

- Define fiber cross section for flexural analysis and perform moment-curvature analysis of the cross section.

- Calculate lateral load versus flexural displacement by integrating curvatures over the height of column (Equations 2 and 3).

- $\quad$ Calculate lateral load versus reinforcement slip displacement (Equations 5 through 7).

- Perform MCFT analysis to lateral load versus shear displacement up to maximum shear strength (Figure 5) while considering the interaction of axial strains due to flexure (Mostafaei \& Kabeyasawa, 2007). Alternatively, an approximate method (Sezen, 2008) can be used and this step can be skipped. Obtain lateral load versus shear displacement envelope (Figure 5).

- Classify the column and combine flexure, slip, and shear responses (Section 3.4, and Figure 7). During calculation of combined or total displacement, at each step, consider the interaction between axial-shear and flexure mechanisms (Section 4 and Figure 8).

\section{Model verification}

The proposed procedure is implemented to evaluate response of previously tested reinforced concrete columns (Sezen, 2002) and predicted responses are compared with experimental test data. The columns tested by (Sezen, 2002) are very useful as these provide experimental force-displacement data for each of the flexure, slip, and shear components individually in addition to the overall response. Hence, the experimental data from these columns are used to validate the component and total deformation models proposed in this study (Lodhi, 2010; Sezen \& Moehle 2006).

These columns were lightly reinforced and had shear and flexural design strengths very close to each other. These are $18 \mathrm{in}$. $(457 \mathrm{~mm})$ square columns with fixed ends at top and bottom having height of 116 in. (2946 mm). The columns had eight No.9 bars and No. 3 column ties with 90-degree end hooks spaced at 12 in. (305 mm). Specimens- 1 and -4 were tested with a constant axial load of $150 \mathrm{kip}(667 \mathrm{KN})$, whereas, Specimen-2 was tested under a constant axial load of $600 \mathrm{kip}(2670 \mathrm{KN})$. The columns were tested under unidirectional cyclic lateral loading, except for Specimen-4, which was tested under monotonically increasing load after few initial cycles of elastic loading. All of the test specimens are modeled with average concrete compressive strength of 3.08 psi $(21.2 \mathrm{MP})$. The yield strength of longitudinal and transverse reinforcement are taken to be $63 \mathrm{ksi}(434 \mathrm{MP})$ and 69 ksi (476 MP), respectively. Other details of test specimens, material properties used for the development of reinforcing steel and unconfined and confined concrete models can be found in (Setzler \& Sezen, 2008; Sezen, 2002, 2008). 
Lateral load-flexural displacement relationships for Specimen-1 and 4 are presented in Figure 10 (a) and 10(b), respectively. In this comparison, test specimens are also analyzed using another displacement component model (Setzler \& Sezen, 2008). This model also treats deformations due to flexure, bar slip and shear individually, however, does not consider softening of concrete compression strength, concrete tensile behavior and buckling of compression bars in flexural analysis. It can be seen that both approaches predict identical pre-peak responses, which matches very well with the experimental data. Peak load and deformation at peak load is also estimated very well by both approaches. For post peak behavior, however, predicted responses are quite different. After reaching the strains corresponding to the start of compression bar buckling, response predicted by the proposed procedure gradually drops and generally follows stiffness of the measured response. The diverging near-peak and post-peak predicted responses by both approaches highlight the need to consider concrete softening and bar buckling effect in the analysis. Figure 10 (c) and 10(d) presents load-displacement relationships due to reinforcement slip for Specimen-1 and 2 , respectively. The predicted responses by displacement component model and proposed method produce almost identical response up until peak load and then diverge in the post peak range. Again, this highlights the need for considering buckling of compression bars in the flexural analysis.

Lateral load-shear displacement relationships for Specimen-1 and 2 are presented in Figure 10(e) and 10(f), respectively. For comparison of the predicted shear responses, the columns are also analyzed with ASFI approach (Mostafaei \& Kabeyasawa, 2007). The predicted responses by ASFI approach and proposed procedure are identical until observed peak and follows experimental data generally well. Peak shear strength is generally captured well by both approaches. For post-peak behavior, proposed model shows strength degradation as deformations increase. In ASFI approach, after reaching peak load, shear deformations are calculated from secant stiffness at peak strength, which is kept constant for post peak behavior. As a result, post-peak predicted shear response in ASFI approach does not show shear strength degradation.

Figure 11 shows the comparison of predicted and experimental lateral load-total displacement relationships for Specimen-1, 2 and 4. Shear strength of Specimen-1 (Figure 11(a)) is calculated as 69.0 kips and flexural strength from moment-curvature analysis is 70.0 kips. Hence, this specimen is classified as category-III column, for which total displacement at any point in the response is sum of flexural, slip and shear displacement at that load step. With the proposed procedure, initial response is predicted very well up to the peak strength. Peak strength and deformation at peak load and the post peak response are captured well. The Specimen-2 (Figure 11(b)) has shear and flexural strengths of 92.0 and 72.0 kips, respectively, and is classified as category-IV column. For this column, shear deformation is frozen at its value at peak strength (flexural strength, $72.0 \mathrm{kips}$ ) and added to flexural and slip displacements for post-peak response. Predicted response by the proposed approach slightly overestimates the pre-peak stiffness and peak load in the positive direction and follows post peak experimental response fairly well in both directions. Specimen-4 (Figure 11(c)) is identical to Specimen-1 except that it was tested under monotonically increasing lateral load after few initial elastic cycles. Comparison of shear and flexural strength classifies this column into category-III column. The predicted response by the proposed procedure follows the trend in experimental data but slightly overestimates the initial stiffness and peak strength. 


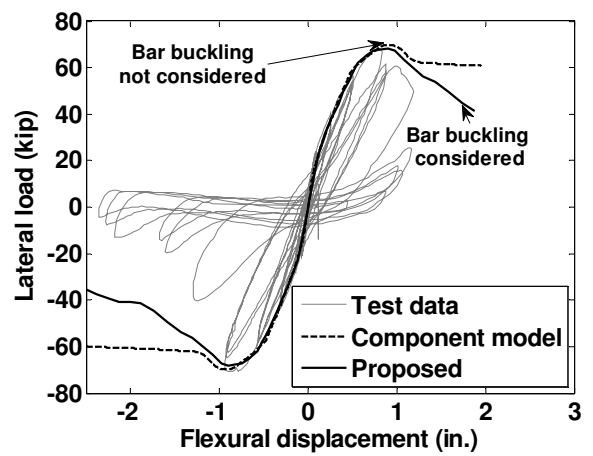

(a)

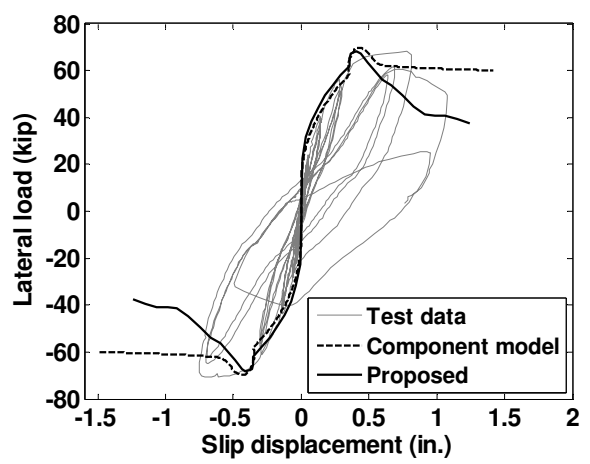

(c)

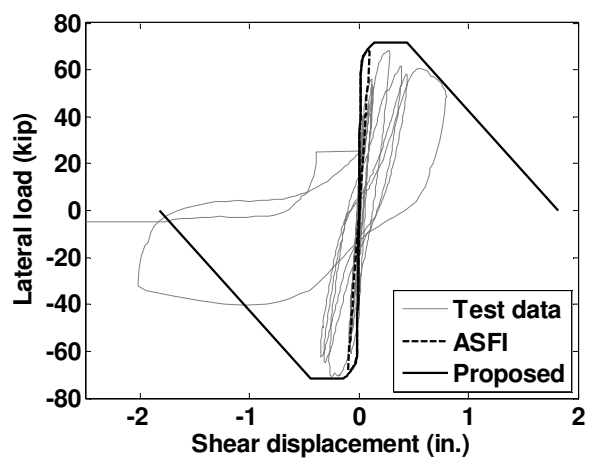

(e)

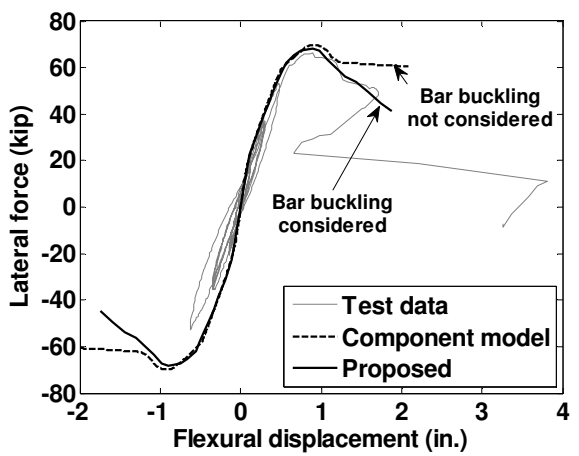

(b)

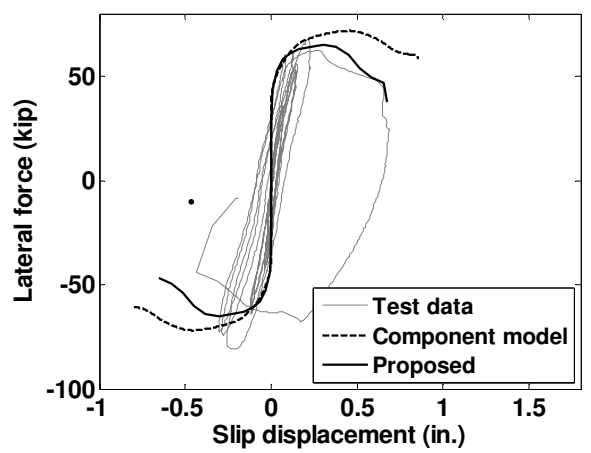

(d)

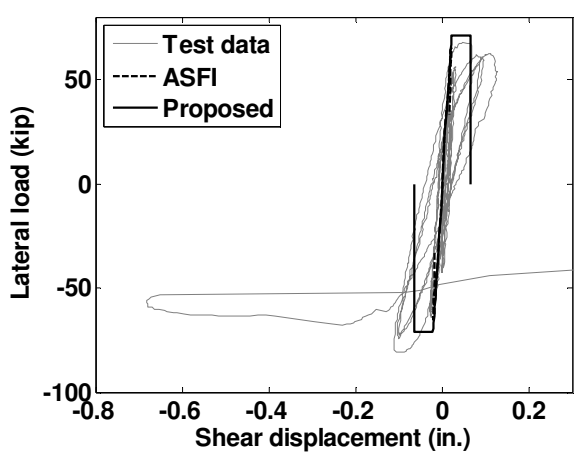

(f)

Fig. 10. Experimental and analytical results for: (a) flexural response of Specimen 1; (b) flexural response of Specimen 4; (c) reinforcement slip response of Specimen 1; (d) reinforcement slip response of Specimen 2; (e) shear response of Specimen 1; and (f) shear response of Specimen 2 


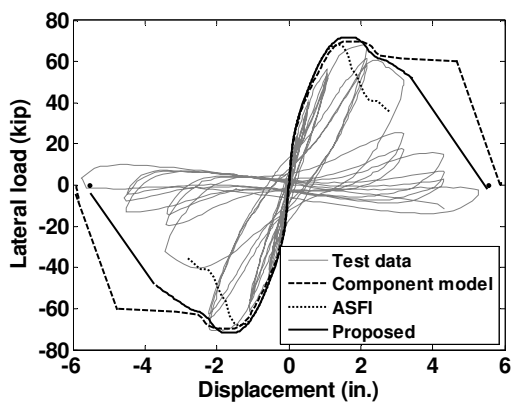

(a)

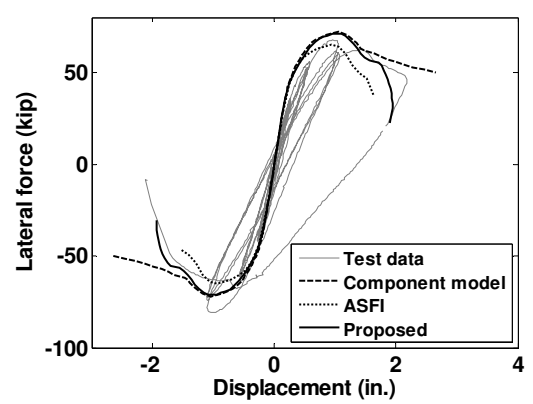

(b)

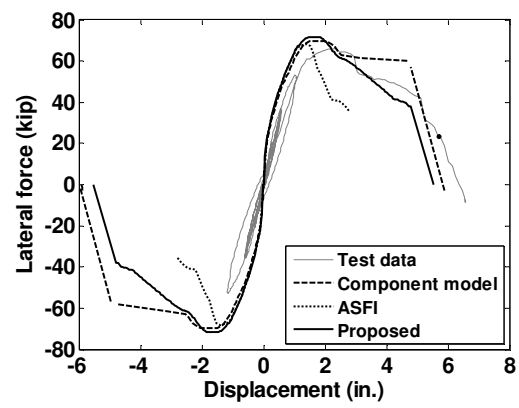

(c)

Fig. 11. Lateral load - displacement relationships : (a) Specimen 1; (b) Specimen 2; and (c) Specimen 4

\section{Conclusions}

A procedure is proposed for response estimation of reinforced concrete columns subjected to lateral loads. The procedure determines flexure, bar slip and shear deformations individually considering interaction between these mechanisms. The axial-flexure mechanism is decoupled from axial-shear model, allowing a relatively simpler analytical procedure. The flexure model in the proposed procedure incorporates concrete tensile behavior, interaction of compression softening and buckling of compression bars into the flexural analysis. The shear model includes the effect of flexural deformation on shear behavior. The pre-peak response is evaluated by employing MCFT, which cannot be used when the strength starts to degrade beyond peak strength. A post peak shear response envelope from displacement component model is adopted for predicting post peak shear behavior. All deformation components, i.e., flexural, bar slip and shear, are added together to get total response of the column. The total/combined peak response is limited by the smaller of the shear and flexural strength of the column and limiting mechanism governs the post peak response. The proposed procedure employs relatively simple calculations for the overall response estimation. The comparison of the predicted and observed responses indicates that the proposed procedure is a suitable displacement-based evaluation process that performs well in predicting the individual displacement components and total response. 


\section{References}

ACI Committee 318. (2008). Building Code Requirements for Structural Concrete (ACI 318-08) and Commentary (ACI 318R-08), American Concrete Institution, ISBN 0-87031-264-2, Farmington Hills, Michigan, USA

Arakawa, T. (1970). Allowable Unit Shearing Stress and Design Method of Shear Reinforcement for Reinforced Concrete Beams. Concrete Journal, Vol.8, No.7, pp. 1120 (in Japanese)

Aydan, O. \& Tano, H. (2011). Shaking-Induced Damage to Buildings by M 9.0 East Japan Mega Earthquake on March 11, 2011, In: Tohoku Pacific Ocean Earthquake and Tsunami - Quick observations from the PEER/EERI/GEER/Tsunami Field Investigation Team, 18.08.2011, Available from: http://www.jsce.or.jp/committee/eec2/eq_repo rt/201103tohoku/Aydan3.pdf

Bentz, E.C. (2000). Sectional Analysis of Reinforced Concrete Members. PhD Thesis, Department of Civil Engineering, University of Toronto, Toronto, Canada, 2000

Ceresa, P.; Petrini, L. \& Pinho, R. (2007). Flexure-shear fiber beam-column elements for modeling frame structures under seismic loading-state of the art. Journal of Earthquake Engineering, Vol. 11, pp. 46-88, ISSN 1363-2469

Ceresa, P.; Petrini, L.; Pinho, R. \& Sousa, R. (2009). A fiber flexure-shear model for seismic analysis of RC-framed structures. Earthquake Engineering and Structural Dynamics, Vol. 38, No. 5, pp. 565-586

Chao, S.H. \& Loh, C.H. (2007). Inelastic response analysis of reinforced concrete structures using modified force analogy method. Earthquake Engineering and Structural Dynamics, Vol. 36, pp. 1659-1683

Earthquake Engineering Research Institute. (December 2005). First Report on the Kashmir Earthquake of October 8, 2005, EERI Special Earthquake Report-December 2005/EERI's Learning from Earthquakes Program, 18.08.2011, Available from: http://www.eeri.org /lfe/pdf/kashmir_eeri_1st_report.pdf

Inoue, K. \& Shimizu, N. (1988). Plastic Collapse Load of Steel Braced Frames Subjected to Horizontal Force. Journal of Structural and Construction Engineering, Vol. 388, pp. 5969 (in Japanese)

Lodhi M.S. (2010). Response estimation of reinforced concrete columns subjected to lateral loads. M.S. Thesis, The Ohio State University, Columbus, Ohio, 2010.

Mid-America Earthquake Center, University of Illinois Urbana-Champaign. (2005). The Kashmir Earthquake of October 8, 2005 - A Quick Look Report, MAE Center Report No. 05-04, 18.08.2011, Available from: http://mae.cee.uiuc.edu/documents/cd_ro m_series/05-04/Report05-04.pdf

Mergos, P.E. \& Kappos, A.J. (2008). A distributed shear and flexural flexibility model with shear-flexure interaction for R/C members subjected to seismic loading. Earthquake Engineering and Structural Dynamics, Vol. 37, PP. 1349-1370

Mergos, P.E. \& Kappos, A.J. (2010). Seismic damage analysis including inelastic shearflexure interaction. Bulletin of Earthquake Engineering, Vol. 8, pp. 27-46

Monti, G. \& Nuti, C. (1992). Non-linear Cyclic Behavior of Reinforcing Bars Including Buckling. Journal of Structural Engineering, Vol. 118, No. 12, pp. 3269-3284

Morsch, E. (1922). Der Eisenbetonbau-Seine Theorie und Anwendung, (5th Edition, Vol. 1, Part 1), Wittwer, Stuttgart, Germany 
Mostafaei, H. \& Kabeyasawa, T. (2007). Axial-Shear-Flexure Interaction Approach for Reinforced Concrete Columns. ACI Structural Journal 2007, Vol. 104, No. 2, pp. 218226

Mostafaei, H. \& Vecchio, F.J. (2008). Uniaxial Shear-Flexure Model for Reinforced Concrete Elements. Journal of Structural Engineering, Vol 134, No. 9, pp. 1538-1547

Mullapudi, T.R. \& Ayoub, A.S. Modeling of the seismic behavior of shear-critical reinforced concrete columns. Engineering Structures 2010; 32:3601-3615.

Mullapudi, T.R.; Ayoub, A.S. \& Belarbi, A. (2008). A fiber beam element with axial, bending and shear interaction for seismic analysis of RC structures, Proceedings of the 14th World Conference on Earthquake Engineering, Beijing, China, 2008

Pacific Earthquake Engineering Research Center/Earthquake Engineering Research Institute/Geotechnical Extreme Event Reconnaissance/Tsunami Field Investigation Team. (2011). Tohoku Pacific Ocean Earthquake and Tsunami - Quick observations from the PEER/EERI/GEER/Tsunami Field Investigation Team, 18.08.2011, Available from: http://peer.berkeley.edu/news/wp-content/uploads/2011/04/T ohoku-short-interim-report.pdf

Patwardhan, C. (2005). Strength and Deformation Modeling of Reinforced Concrete Columns. M.S.Thesis, The Ohio State University, Columbus, Ohio, 2005

Potger, G.M.; Kawano, A.; Griffith, M.C. \& Warner, R.F. (2001). Dynamic Analysis of RC Frames Including Buckling of Longitudinal Steel Reinforcement, Proceedings of the NZSEE Conference, 2001, Paper No. 4.12.01

Priestley, M.J.N.; Calvi, G.M. \& Kowalsky, M.J. (2007). Displacement-Based Seismic Design of Structures, IUSS Press, Pavia, Italy

Ritter, W. (1899). Die Bauweise Hennebique. Schweizerische Bbauzeitung, Vol. 33, No. 7, pp 59-61

Schlaich, J.; Schafer, I. \& Jennewein, M. (1987). Towards a Consistent Design of Structural Concrete. Journal of the Prestressed Concrete Institute, Vol. 32, No. 3, pp. 74-150

Setzler, E.J. \& Sezen, H. (2008). Model for the lateral behavior of reinforced concrete columns including shear deformations. Earthquake Spectra, Vol. 24, No. 2, pp. 493-511

Sezen H., and Moehle J.P. (2006). Seismic tests of concrete columns with light transverse reinforcement. ACI Structural Journal, Vol. 103, No. 6, pp. 842-849

Sezen, H. (2002). Seismic Behavior and Modeling of Reinforced Concrete Building Columns. Ph.D Thesis, University of California, Berkeley, 2002

Sezen, H. (2008). Shear deformation model for reinforced concrete columns. Structural Engineering and Mechanics, Vol. 28, No. 1, pp. 39-52

Sezen, H., \& Moehle, J.P. (2004). Strength and deformation capacity of reinforced concrete columns with limited ductility, Proceedings of the 13th World Conference on Earthquake Engineering, Vancouver, Canada, 2004

Sezen, H. \& Moehle, J.P. (2004). Shear Strength Model for Lightly Reinforced Concrete Columns. Journal of Structural Engineering, Vol. 130, No. 11, pp. 1692-1703

Sezen, H. \& Setzler, E.J. (2008). Reinforcement Slip in Reinforced Concrete Columns. ACI Structural Journal, Vol. 105, No. 3, pp. 280-289

Structural Engineers Association of California (SEAOC). (2002). Performance based seismic design engineering of buildings. Vision 2000 Report, Sacramento, CA, USA

Takewaki, I.; Murakami, S.; Fujita, K.; Yoshitomi, S. \& Tsuji, M. (2011). The 2011 off the Pacific coast of Tohoku earthquake and response of high-rise buildings under long- 
period ground motions. Soil Dynamics and Earthquake Engineering, doi:10.1016/j.soil dyn.2011.06.001 (In press)

U.S Geological Survey/Earthquake Engineering Research Institute Advance Reconnaissance Team. (February 23, 2010). The $\mathrm{M}_{\mathrm{w}} 7.0$ Haiti Earthquake of January 12, 2010, USGS/EERI Team Report V.1.1, 18.08.2011, Available from: http:/ / www.eqclearingh ouse.org/20100112-haiti/wp-content/uploads/2010/02/USGS_EERI_HAITI_V1.1. pdf

Vecchio, F.J. (1989). Nonlinear finite element analysis of reinforced concrete membranes. ACI Structural Journal, Vol. 86, No. 1, pp. 26-35

Vecchio, F.J. (2000). Disturbed stress field model for reinforced concrete: formulation. Journal of Structural Engineering, Vol. 126, No. 9, pp. 1070-1077

Vecchio, F.J. \& Collins, M.P. (1986). The modified compression field theory for reinforced concrete elements subjected to shear. ACI Journal Proceedings, Vol. 83, No. 2, pp. 219-231

Vecchio, F.J. \& Collins, M.P. (1988). Predicting the Response of Reinforced Concrete Beams Subjected to Shear Using Modified Compression Field Theory. ACI Structural Journal, Vol. 85, No. 3, pp. 258-268

Williams, M.S. \& Sexsmith, R.G. (1995). Seismic Damage Indices for Concrete Structures: A State-of-the-Art Review. Earthquake Spectra, Vol. 11, No. 2, pp. 319-349

Xu, S.Y. \& Zhang, J. (2011). Hysteretic shear-flexure interaction model of reinforced concrete columns for seismic response assessment of bridges. Earthquake Engineering and Structural Dynamics, Vol. 40, pp. 315-337

Zhang, J.; Xu, S.Y. \& Tang, Y. (2010). Inelastic displacement demand of bridge columns considering shear-flexure interaction. Earthquake Engineering and Structural Dynamics, DOI 10.1002/eqe.1056 


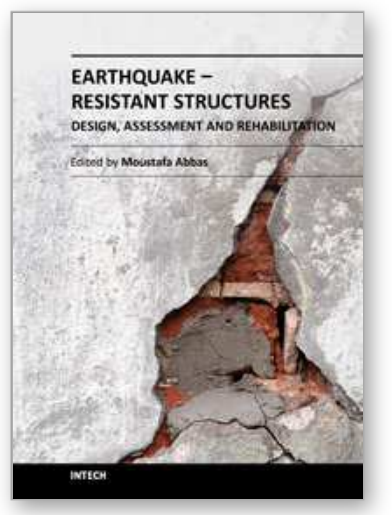

\section{Earthquake-Resistant Structures - Design, Assessment and Rehabilitation}

Edited by Prof. Abbas Moustafa

ISBN 978-953-51-0123-9

Hard cover, 524 pages

Publisher InTech

Published online 29, February, 2012

Published in print edition February, 2012

This book deals with earthquake-resistant structures, such as, buildings, bridges and liquid storage tanks. It contains twenty chapters covering several interesting research topics written by researchers and experts in the field of earthquake engineering. The book covers seismic-resistance design of masonry and reinforced concrete structures to be constructed as well as safety assessment, strengthening and rehabilitation of existing structures against earthquake loads. It also includes three chapters on electromagnetic sensing techniques for health assessment of structures, post earthquake assessment of steel buildings in fire environment and response of underground pipes to blast loads. The book provides the state-of-the-art on recent progress in earthquake-resistant structures. It should be useful to graduate students, researchers and practicing structural engineers.

\section{How to reference}

In order to correctly reference this scholarly work, feel free to copy and paste the following:

Halil Sezen and Muhammad S. Lodhi (2012). Seismic Response of Reinforced Concrete Columns, Earthquake-Resistant Structures - Design, Assessment and Rehabilitation, Prof. Abbas Moustafa (Ed.), ISBN: 978-953-51-0123-9, InTech, Available from: http://www.intechopen.com/books/earthquake-resistantstructures-design-assessment-and-rehabilitation/seismic-response-of-reinforced-concrete-columns-

\section{INTECH}

open science | open minds

\author{
InTech Europe \\ University Campus STeP Ri \\ Slavka Krautzeka 83/A \\ 51000 Rijeka, Croatia \\ Phone: +385 (51) 770447 \\ Fax: +385 (51) 686166 \\ www.intechopen.com
}

\author{
InTech China \\ Unit 405, Office Block, Hotel Equatorial Shanghai \\ No.65, Yan An Road (West), Shanghai, 200040, China \\ 中国上海市延安西路65号上海国际贵都大饭店办公楼405单元 \\ Phone: +86-21-62489820 \\ Fax: $+86-21-62489821$
}


(C) 2012 The Author(s). Licensee IntechOpen. This is an open access article distributed under the terms of the Creative Commons Attribution 3.0 License, which permits unrestricted use, distribution, and reproduction in any medium, provided the original work is properly cited. 